$\xi=\mathrm{\alpha}$

\title{
Hepatoprotective effect of aqueous extract of cardamom against gentamicin induced hepatic damage in rats
}

\author{
Mohamed Aboubakr*, Abdelazem Mohamed Abdelazem \\ Department of pharmacology, Faculty of Veterinary Medicine, Benha University, 13736 Moshtohor, Toukh, Qaliobiya, Egypt \\ *Corresponding author E-mail: mohamed.aboubakr@fvtm.bu.edu.eg
}

\begin{abstract}
The study was designed to evaluate the hepatoprotective activity of aqueous extract of cardamom in acute experimental liver injury induced by gentamicin. Twenty four male albino rats were randomly divided into four groups (six rats in each). Animals of the first group served as control and orally (p.o.) received (1 ml/kg saline). The second experimental group was given gentamicin (80 mg/kg i.p.) for 7 days. Third and fourth groups were given aqueous extract of cardamom $(100$ and $200 \mathrm{mg} / \mathrm{kg}$ p.o. $)+$ gentamicin for 7 days, respectively. The degree of hepatoprotection was measured using serum aspartate aminotransferase (AST), alanine aminotransferase (ALT), bilirubin, albumin, and lipid profile levels. In the acute liver damage induced by gentamicin, cardamom aqueous extracts (100 and $200 \mathrm{mg} / \mathrm{kg}$, p.o.) significantly reduced the elevated serum levels of AST, ALT, bilirubin, cholesterol, triglycerides and low density lipoprotein cholesterol (LDL-chol) in gentamicin induced hepatotoxicity. Also cardamom aqueous extracts $(100 \& 200 \mathrm{mg} / \mathrm{kg}$, p.o. $)$ significantly increased the lowered serum levels of albumin and high density lipoprotein cholesterol (HDL-chol) in gentamicin induced hepatotoxicity rats. Histopathological examination of the liver tissues supported the hepatoprotection. Our findings concluded that cardamom aqueous extracts possessed hepatoprotective activity against gentamicin induced hepatotoxicity in rats.
\end{abstract}

Keywords: Cardamom; Hepatoprotective; Gentamicin; Liver Damage; Rats.

\section{Introduction}

The importance of traditional systems of medicine and of certain traditional medical practices has now been recognized all over the world. Today, it is required to have an intelligent and pragmatic approach to evaluate selective drugs of herbal origin. Therefore, it should really matter for Pharmacologists to obtain information from traditional healers, about their remedies and to extract the active principles for development into drugs [1].

Cardamom the seeds of their ripe fruits of Elettaria cardamomum, are widely used for flavoring purposes in food and as carminative. In medicine it is used to treat gastrointestinal disorders [2]. Despite its wide uses, little information has been reported on their pharmacological properties, which showed antioxidant [3-4] and anti-inflammatory activity [5]. Antimicrobial activity of cardamom was attributed to its essential oil [6-7]. Recently, cardamom showed gastroprotective effects against aspirin and ethanol induced lesions in rats [2].

The liver is the largest internal organ in the body and played a vital role in the detoxification of harmful substances. It has regulatory effect on the many important metabolic functions and is responsible for maintaining homeostasis of the body [8].

Gentamicin is an aminoglycoside antibiotic that is commonly used to treat life-threatening bacterial infections. Its broad-spectrum activity against aerobic gram positive and gram negative bacteria, chemical stability and rapid onset of bactericidal action has often made it a drug of choice to treat a variety of clinical cases [9]. However, one of the side effects of gentamicin usage is its potential to induce hepatotoxicity.
Hence, the goal of the present research work was to study if the hepatotoxicity induced by gentamicin can be ameliorated by the use of cardamom aqueous extract.

\section{Materials and methods}

\subsection{Medicinal plant (cardamom)}

Cardamom (Elettaria cardmomum), seeds were purchased from the local market of Agricultural Herbs, Spices and Medicinal plants, Cairo, Egypt. The dried plant materials were grinded into a fine powder and kept till the preparation of aqueous extract.

\subsection{Preparation of aqueous extract}

Air-dried powder $(10 \mathrm{~g})$ of the respective plant seeds was mixed well in $100 \mathrm{ml}$ sterilized distilled water and kept at room temperature for $24 \mathrm{~h}$ on an orbital shaker with $150 \mathrm{rpm}$. The solution was further filtered using muslin cloth. The filtrate was centrifuged at $5000 \mathrm{rpm}$ for $15 \mathrm{~min}$. The supernatant thus obtained was filtered through Whattman filter No. 1 under strict aseptic conditions and the filtrate was collected in a preweighed sterilized test tube. Aqueous extracts were prepared in final concentration of 100 $\mathrm{mg} / \mathrm{ml}$. Test tubes were cotton plugged and stored in refrigerator until further used [10].

\subsection{Experimental rats}

Twenty four male albino rats (160-190 g) were obtained from the Animal House, Faculty of Veterinary Medicine, Benha University, Egypt. They were maintained on standard pellet diet and tap water 
ad libitum and were kept in plastic cages under a $12 \mathrm{hr}$ light/dark cycle and room temperature $22-24^{\circ} \mathrm{C}$. Rats were acclimatized to the environment for two week prior to experimental use. This investigation was approved by the Animal Research Ethics Committee.

\subsection{Experimental protocol}

Rats were divided into the four groups; each group consisted of 6 animals and they received the treatment as follows:

Group I: Control (1 ml/kg Saline p.o.).

Group II: Gentamicin ( $80 \mathrm{mg} / \mathrm{kg}$ i.p.) for 7 days.

Group III: Aqueous extract of cardamom (100 mg/kg p.o.) + Gentamicin for 7 days.

Group IV: Aqueous extract of cardamom (200 mg/kg p.o.) + Gentamicin for 7 days.

Gentamicin $\left(\right.$ Garamycin $\left.^{\circledR}\right)$, it was obtained from Memphis Company for Pharmaceutical and Chemical Industries, Cairo, Egypt. It is dispensed in the form of ampoules; each containing $40 \mathrm{mg} / \mathrm{ml}$. Rats wereintraperitoneally administered with gentamicin in a dose of $80 \mathrm{mg} / \mathrm{kg}$ to induce acute hepatotoxicity [11].

\subsection{Blood samples for biochemical estimation}

At the end of experimental period, rats were anaesthetized with ether. Blood samples were collected from retro orbital venous plexus in non-heparinized tubes, centrifuged at $3000 \mathrm{rpm}$ for 20 minutes, and blood sera were collected and stored at $4{ }^{\circ} \mathrm{C}$ prior immediate determination of serum biochemical constituents which was performed by using ready-made kits from Diamond diagnostics company (Egypt), Vitro Scient Diagnostic Company (Egypt) and SPINREACT Company (Spain).The biochemical measurements were performed for estimation of the activities of Aspartate Aminotransferase (AST) and Alanine Aminotranseferase (ALT), albumin, bilirubin, cholesterol, triglycerides, High Density Lipoprotein-cholesterol (HDL-chol) and Low Density Lipoprotein-cholesterol (LDL-chol).

\subsection{Histopathological examination}

Following complete necropsy of the experimental male rats, small fresh specimens from liver collected and rapidly fixed in $10 \%$ formalin solution for at least $24 \mathrm{hrs}$. After that, these specimenswere processed through the convential paraffin embedding technique (dehydration in ascending grades of ethylalcohol, clearing in different changes of xylene and embedding in different changes of meltedparaffin wax at $60{ }^{\circ} \mathrm{C}$ ). Paraffin blocks were cutted by microtome into 5 microns, thick sections which were stained by Haematoxylin and Eosin (H.E.) according to the method described by [12].

\subsection{Statistical analysis}

The data were expressed as (mean \pm SE) and analyzed using SPSS (Statistical Package for the Social Sciences, version 15.0, Illinois, Chicago, USA) and differences between the averages were examined by Duncan's multiple range test. Mean values within a rowwith different superscript letters are significantly different $(\mathrm{P} \leq$ $0.05)$.

\section{Results}

Intraperitoneal administration of gentamicin at a dose of $80 \mathrm{mg} / \mathrm{kg}$ caused a significant increase in liver parameters (ALT, AST, bilirubin, cholesterol, triglycerides, LDL-chol) and a significant decrease in albumin and HDL-chol in comparison with control values. In cardamom treated groups these biochemical parameters were returned towards the normal values. The biochemical parameters were recorded in Table 1.

Light microscopic examination of the liver in control rats showed the normal structure (Figure 1A). Histopathological effects of gentamicin on liver of treated rats are presented in Figure 1B. Liver treated with aqueous extract of cardamom showed decrease in the sever histopathological changes caused by gentamicin (Figure $1 \mathrm{C}$ and $1 \mathrm{D})$.

Table 1: Effect of oral administration of aqueous extract of cardamom (100 and $200 \mathrm{mg} / \mathrm{kg} \mathrm{b.wt.} \mathrm{on} \mathrm{some} \mathrm{biochemical} \mathrm{parameters} \mathrm{in} \mathrm{gentamicin} \mathrm{induced}$ hepatotoxicity in rats $(n=6)$.

\begin{tabular}{|c|c|c|c|c|}
\hline Parameters & Control & Gentamicin & $\begin{array}{c}\text { Cardamom (100 mg/kg p.o.) } \\
+ \text { gentamicin (i.p.) }\end{array}$ & $\begin{array}{c}\text { Cardamom (200 mg/kg p.o.) } \\
+ \text { gentamicin (i.p.) }\end{array}$ \\
\hline $\begin{array}{l}\text { AST } \\
(\mathrm{U} / \mathrm{L})\end{array}$ & $41.32 \pm 2.01^{\mathrm{d}}$ & $87.29 \pm 2.94^{\mathrm{a}}$ & $64.62 \pm 2.87^{\mathrm{b}}$ & $57.49 \pm 2.51^{\mathrm{c}}$ \\
\hline $\begin{array}{l}\mathrm{ALT} \\
(\mathrm{U} / \mathrm{L})\end{array}$ & $31.64 \pm 1.92^{\mathrm{d}}$ & $58.13 \pm 2.07^{\mathrm{a}}$ & $49.62 \pm 2.11^{\mathrm{b}}$ & $42.27 \pm 1.94^{\mathrm{c}}$ \\
\hline $\begin{array}{l}\text { T. bilirubin } \\
(\mathrm{mg} / \mathrm{dl})\end{array}$ & $0.51 \pm 0.05^{\mathrm{d}}$ & $0.86 \pm 0.09^{\mathrm{a}}$ & $0.79 \pm 0.06^{\mathrm{b}}$ & $0.71 \pm 0.08^{\mathrm{c}}$ \\
\hline $\begin{array}{l}\text { Albumin } \\
(\mathrm{g} / \mathrm{dl})\end{array}$ & $4.59 \pm 0.19^{\mathrm{a}}$ & $3.54 \pm 0.15^{\mathrm{d}}$ & $4.01 \pm 0.14^{\mathrm{bc}}$ & $4.09 \pm 0.17^{\mathrm{bc}}$ \\
\hline $\begin{array}{l}\text { Cholesterol } \\
(\mathrm{mg} / \mathrm{dl})\end{array}$ & $91.81 \pm 4.01^{\mathrm{d}}$ & $156.39 \pm 5.42^{\mathrm{a}}$ & $115.68 \pm 5.63^{b}$ & $101.09 \pm 4.64^{\mathrm{c}}$ \\
\hline $\begin{array}{l}\text { Triglycerides } \\
(\mathrm{mg} / \mathrm{dl})\end{array}$ & $79.05 \pm 3.85^{\mathrm{d}}$ & $98.07 \pm 4.16^{\mathrm{a}}$ & $87.62 \pm 4.23^{\mathrm{bc}}$ & $88.91 \pm 5.01^{\mathrm{bc}}$ \\
\hline $\begin{array}{l}\text { HDL-Chol } \\
(\mathrm{mg} / \mathrm{dl})\end{array}$ & $53.34 \pm 3.47^{\mathrm{a}}$ & $38.74 \pm 3.05^{\mathrm{d}}$ & $44.45 \pm 3.98^{\mathrm{bc}}$ & $45.09 \pm 3.19^{\mathrm{bc}}$ \\
\hline $\begin{array}{l}\text { LDL-Chol } \\
(\mathrm{mg} / \mathrm{dl})\end{array}$ & $36.57 \pm 3.25^{\mathrm{d}}$ & $57.81 \pm 4.11^{\mathrm{a}}$ & $49.38 \pm 4.81^{\mathrm{b}}$ & $42.57 \pm 5.13^{\mathrm{c}}$ \\
\hline
\end{tabular}

a, b, c, d Mean values having different letters in the same row differ significantly $(\mathrm{P}<0.05)$. 


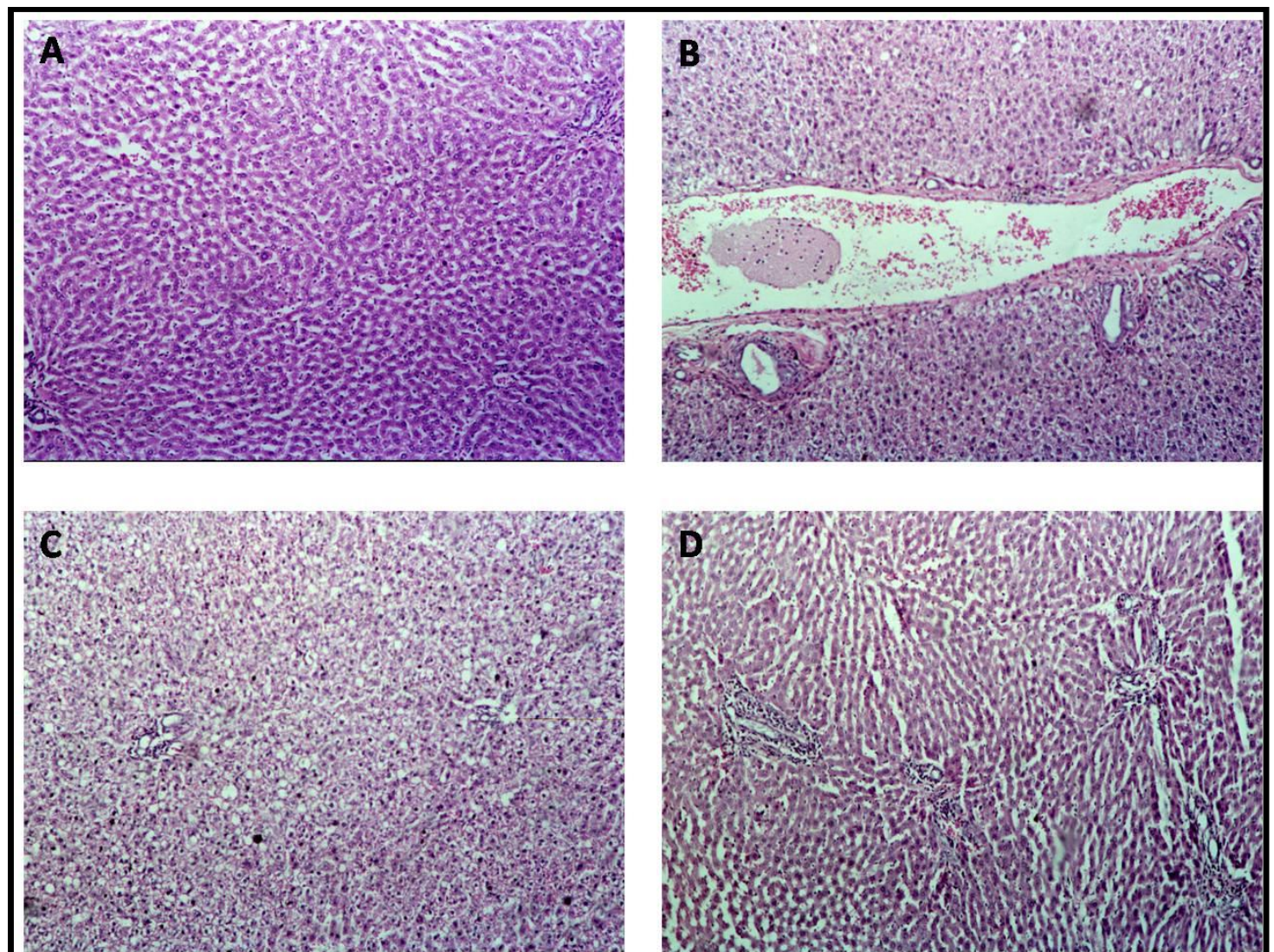

Fig. 1: Histopathology showing the alterations induced with gentamicin and preventive effects of cardamom in hepatic tissues of rats. (A) Hepatic section showing the normal architecture of portal vein and normal hepatocytes arranged in trabaculae. (B) Gentamicin ( $80 \mathrm{mg} / \mathrm{kg}$ b.wt) induced injuries in liver with severe congestion of portal blood vessels with fibrin emboli. (C) Cardamom (100 mg/kg b.wt) + gentamicin; reduced injuries of gentamicin and showing fatty changes in some hepatocytes and others show hydropic degeneration. (D) Cardamom $(200 \mathrm{mg} / \mathrm{kg} \mathrm{b}$.wt $)+\mathrm{gentamicin}$; showing periductal inflammatory cells. The stain was $(\mathrm{H} \& \mathrm{E} \times 200)$.

\section{Discussion}

Hepatotoxicty or liver damage is the irregular functioning of the liver; with mitochondrial dysfunction reported as one of the major mechanism of drugs induce hepatotoxicity. By severely altering mitochondrial function in the liver, drugs can induce hepatic necrosis, causing cystolytic hepatitis, and can progress into liver failure[13].

Results of this study confirmed that gentamicin at a dose of 80 $\mathrm{mg} / \mathrm{kg}$ produces significant hepatotoxicity as evidenced by increase in serum AST, ALT, bilirubin and lipid profile and significant decrease in albumin and HDL-chol. In addition, gentamicin induced severe hepatic damages as shown in histopathological examination. Similar findings were observed after administration of gentamicin for 7 days which resulted in damage of liver structure with disarrangement of hepatic strands [11].

AST predominantly found in mitochondria of hepatocytes. ALT is more specific to liver, and thus is a better parameter for detecting liver injury. Serum bilirubin is also associated with liver cell damage. The ALT, AST and serum bilirubin level are largely used as most common biochemical markers to evaluate liver injury [14].

The significant decrease in activities of these enzymes by cardamom extract may indicate that the plant extracts did not have necrotic effect on the liver. This may be due to the fact that the extracts offer protection and maintain the functional integrity of hepatic cells.

Bilirubin is released from the destroyed red blood cells and passed on to the liver. The liver excretes the bilirubin in the fluid called bile. If the liver is not functioning properly, the bilirubin will not be properly excreted. Therefore, if the bilirubin level is higher than normal, it may mean that the liver is not functioning correctly [15]. The amount of albumin in gentamicin treated rats showed a significant decrease compared to control group [16].

Serum bilirubin is considered an index for the assessment of hepatic function and any abnormal increase indicates hepatobiliary disease and severe disturbance of hepatocellular architecture [17]. Gentamicin administration resulted in increased serum bilirubin level, thereby suggesting severe hepatic injury and confirming the hepatotoxic nature of gentamicin. Treatment with cardamom extract significantly decreased the elevated level of total bilirubin in serum towards normalcy indicating its hepatoprotective efficacy. Treatment with cardamom recovered the injured liver to normal which indicate that cardamom has antihepatotoxic effect.

Gentamicin enhanced the production of superoxide anion, hydrogen peroxide and hydroxyl radicals by mitochondria [18]. Free radicals cause Peroxidation of phospholipids membrane, DNA strand breakage, protein denaturation. Treatment of rats with cardamom effectively decreased liver enzyme levels in the serum. This can be attributed to the presence of phenolic compounds in cardamom that can act by scavenging free radicals [19].

Assessment of lipid profile is required for the state of wellbeing of every individual as cardiovascular diseases and coronary heart diseases are silent, serial killers of our age [20]. Lipids (cholesterol, triglycerides and LDL-chol) levels were increased significantly in the serum of gentamicin intoxicated rats group, while HDL-chol was decreased. The possible explanation of the observed hyperlipidemia might reflect the impairment of liver cells to metabolize lipids or lipid peroxidation [21]. The increase in serum lipids may be attributed to the increased hepatic synthesis and / or reduced of lipoprotein lipase [22]. Cardamom pre-treat rats prevented the gentamicin induced rise in serum lipids. These findings demonstrated its protective action on hepatic injury induced by gentamicin. Similarly, treatment with silymarin [23-24] significantly lowered serum cholesterol content in animals received paracetamol or $\mathrm{CCl}_{4}$, respectively.

The main constituents in cardamom are antioxidants such as tocopherol, phenolic acids, indole-3-carbinol, and volatile organic compounds [25]. The lowering effect of cardamom on cholesterol and triglyceride levels reflected its protective hepatocellular effects and the ability of the phenolic contents and essential oil to 
reduce the hyperlipidemia [26]. Furthermore, it has been reported that spices may inhibit hepatic 3-hydroxyl-3-methylglutaryl coenzyme A reductase activity, resulting in lowering hepatic and serum cholesterol levels [27].

\section{Conclusions}

The present findings show that oral administration of aquoues extract of cardamom produces significant hepatoprotective effects in gentamicin-treated rats. Further investigations are required to explore exactly the mechanism action of cardamom against gentamicin induced physiological disturbances and histopathological changes.

\section{Acknowledgment}

The authors wish to thank Prof. Dr: Adel Bakeer (Department of pathology, Faculty of Veterinary Medicine, Cairo University, Egypt) for his help in histopathological study.

\section{Conflict of interest}

The authors declare that there is no conflict of interests regarding the publication of this article.

\section{References}

[1] A. Muthuraman, S. Sood, and S.K. Singla, The antiinflammatory potential of phenolic compounds from Emblica officinalis L. in rat.

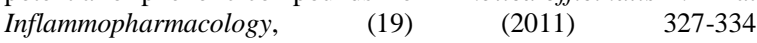
http://dx.doi.org/10.1007/s10787-010-0041-9.

[2] A. Jamal, K. Javed, M. Aslam, and M.A. Jafri, Gastroprotective effect of cardamom, Elettaria cardamomum Maton fruits in rats. Journal of Ethnopharmacology, (103)(2006) 149153.http://dx.doi.org/10.1016/j.jep.2005.07.016.

[3] I. Hinneburg, H.J.D. Dorman, and R. Hiltunen, Antioxidant activities of extracts from selected culinary herbs and spices. Food Chemistry, (97) (2006) 122 129.http://dx.doi.org/10.1016/j.foodchem.2005.03.028.

[4] M.N. Vasavada, S. Dwivedi, and D. Cornforth, Evaluation of garam masala spices and phosphates as antioxidants in cooked ground beef. Journal of Food Science, (71) (2006) C292C297.http://dx.doi.org/10.1111/j.1750-3841.2006.00039.x.

[5] H. Al-Zuhair, B. El-Sayeh, H.A. Ameen, and H. Al-Shoora, Pharmacological studies of cardamom oil in animals. Pharmacological Research, (34) 7982.http://dx.doi.org/10.1006/phrs.1996.0067.

[6] A. Ramadan, N.A. Afifi, M.M. Fathy, E.A. El-Kashoury, and E.V. El-Naeneey, Some pharmacodynamic effects and antimicrobial activity of essential oils of certain plants used in Egyptian folk medicine. Veterinary Medical Journal, (42) (1994) 263-270.

[7] S.C. Garg, and R.K. Jain, Antimicrobial efficacy of essential oil of Elettaria cardamomum. Indian Perfumer, (45) (2001) 115-117.

[8] C. Mayuren, V.V. Reddy, S.V. Priya, and V.A. Devi, Protective effect of Livactine against $\mathrm{CCL}_{4}$ and paracetamol induced hepatotoxicity in adult Wister rats. North American Journal of Medical Sciences, (2) (2010) 492-495.

[9] G.B. Appel, Aminoglycoside nephrotoxicity. American Journal of Medicine, (88) (1990) 165-205.http://dx.doi.org/10.1016/00029343(90)90082-o.

[10] P. Kaushik, P. Goyal, A. Chauhan, and G. Chauhan, In Vitro Evaluation of Antibacterial Potential of Dry Fruit Extracts of Elettariacardamomum Maton (Chhoti Elaichi). Iranian Journal of Pharmaceutical Research (9) (2010) 287-292.

[11] A. Noorani, K. Gupta, K. Bhadada, and M.K. Kale, Protective Effect of Methanolic Leaf Extract of Caesalpinia Bonduc (L.) on Gentamicin-Induced Hepatotoxicity and Nephrotoxicity in Rats. Iranian Journal of Pharmacology and Therapeutics, (10) (2011) 21-25.

[12] M.L. Harries, Carleton's Histopathological Technique $5^{\text {th }}$ Ed. Oxford Univ Press, New York, Toronto, (1989) pp. 33-48.

[13] A. Jain, and A.K. Singhai, Effect of Momordica dioica Roxb on gentamicin model of acute renal failure. Natural Product Research
(24)

(2010)

1379

1389.http://dx.doi.org/10.1080/14786410802267569.

[14] C. Girish, B.C. Koner, S. Jayanthi, K.R. Rao, B. Rajesh, and S.C Pradhan, Hepatoprotective activity of picroliv, curcumin and ellagic acid compared to silymarin on paracetamol induced liver toxicity in mice. Indian Journal of Medical Research, (129) (2009) 569578.http://dx.doi.org/10.1111/j.1472-8206.2009.00722.x.

[15] D.E. Baranano, M. Rao, C.D. Ferris, and S.H. Synder, Biliverdinreductase: a major physiologic cytoprotectant. Proceedings of the $\mathrm{Na}$ tional Academy of Science of the United States of America, (99) (2002) 16093-16098.http://dx.doi.org/10.1073/pnas.252626999.

[16] N. Mahmood, M. Haleh, P. Mohammad, F. Mohsen, and K.J. Hossein, Pathological changes of gentamicin in liver tissue and antioxidant property of cinnamon extract on wistar rats. Biomedical and Pharmacology Journal. (7) (2014) 341-347.

[17] P. Martin, and L.S. Friedman, Assessment of liver function and diagnostic studies, In: Freidman L S and Keefe E B (Eds.), Hand Book of Liver Disease. Churchill Livingstone, Philadelphia, (1992) pp.1-14.

[18] C. Yang, X. Du and Y. Han, Renal cortical mitochondria are the source of oxygen free radicals enhanced by gentamicin. Renal Failure (17) 21-26. http://dx.doi.org/10.3109/08860229509036371.

[19] M.A. Abdel-Wahhab and S.E. Aly, Antioxidant property of Nigella sativa (black cumin) and Syzygium aromaticum (clove) in rats during aflatoxicosis. Journal of Applied Toxicology, (25) (2005) 218 223. http://dx.doi.org/10.1002/jat.1057.

[20] O.D. Omodamiro and C.I. Nwankwo, The effect of Voacanga africana leaves extract on serum lipid profile and haematological parameters on albino wistar rats. European Journal of Experimental Biology (3) (2013) 140-148.

[21] E.G.E. El-Sahar, and A.M.M. Abed El-Rahman, Hepatoprotective activity of different doses of Spirulina against ccl4 induced liver damage in rats. Journal of American Science, (8) (2012) 916-924.

[22] N. Mathur, V. Chaudhary, M. Mehta, and S. Gupta, Sunset yellow induced changes in the lipid profile in male albino rat. Biochemical and cellular archives, (5) (2005) 197-200.

[23] S. RamachandraSetty, A.A. Quereshi, A.H.M. ViswanathSwamy, T. Patil, T. Prakash, K. Prabhu, and A, Veeran Gouda, Hepatoprotective activity of Calotropis procera flowers against paracetamolinduced hepatic injury in rats. Fitoterapia, (78) (2007) 451-454.

[24] Y.W. Hsu, C.F. Tsai, W.K. Chen, and F.J. Lu, Protective effects of sea buckthorn (Hippophaer hamnoidesL.) seed oil against carbon tetrachloride-induced hepatotoxicity in mice. Food and Chemical Toxicology, (47) 22812288.http://dx.doi.org/10.1016/j.fct.2009.06.015.

[25] A. Acharya, I. Das, S. Singh and Saha T, Chemopreventive properties of indole-3-carbinol, diindolylmethane and other constituents of cardamom against carcinogenesis. Recent Patents on Food, Nutrition \& Agriculture, (2) (2010) 166 177.http://dx.doi.org/10.2174/2212798411002020166.

[26] E.A. Sadeek and F.H. Abd El-Razek, the Chemo-Protective Effect of Turmeric, Chili, Cloves and Cardamom on Correcting Iron Overload-Induced Liver Injury, Oxidative Stress and Serum Lipid Profile in Rat Models. Journal of American Science, (6) (2010) 702 712.

[27] S. Shobana and K.A. Naidu, Antioxidant activity of selected Indian spices. Prostaglandins LeukotEssent Fatty Acids (62) (2000) $107-$ 110.http://dx.doi.org/10.1054/plef.1999.0128. 